\title{
Relationship between Fetal Station and Successful Vaginal Delivery in Nulliparous Women
}

\author{
Sally Y. Segel, M.D. ${ }^{1}$, Carlos A. Carreño, M.D. ${ }^{2}$, Steven J. Weiner, M.S. ${ }^{15}$, Steven L. Bloom, \\ M.D. ${ }^{3}$, Catherine Y. Spong, M.D. ${ }^{16}$, Michael W. Varner, M.D. ${ }^{4}$, Dwight J. Rouse, M.D. ${ }^{5}$, Steve \\ N. Caritis, M.D. ${ }^{6}$, William A. Grobman, M.D. ${ }^{7}$, Yoram Sorokin, M.D. ${ }^{8}$, Anthony Sciscione, \\ D.O. ${ }^{9}$, Brian M. Mercer, M.D. ${ }^{10}$, John M. Thorp, M.D. ${ }^{11}$, Fergal D. Malone, M.D. ${ }^{12}$, Margaret \\ Harper, M.D., M.S. ${ }^{13}$, Jay D. lams, M.D. ${ }^{14}$, and Eunice Kennedy Shriver National Institute of \\ Child Health and Human Development Maternal-Fetal Medicine Units Network
}

\begin{abstract}
${ }^{1}$ Department of Obstetrics and Gynecology at the Oregon Health and Science University, Portland, Oregon ${ }^{2}$ The University of Texas Health Science Center at Houston, Houston, Texas ${ }^{3}$ University of Texas Southwestern Medical Center, Dallas, Texas ${ }^{4}$ University of Utah, Salt Lake City, Utah ${ }^{5}$ University of Alabama at Birmingham, Birmingham, Alabama ${ }^{6}$ University of Pittsburgh, Pittsburgh, Pennsylvania ${ }^{7}$ Northwestern University, Chicago, Illinois ${ }^{8}$ Wayne State University, Detroit, Michigan ${ }^{9}$ Drexel University, Philadelphia, Pennsylvania ${ }^{10}$ Case Western Reserve University-Metro Health Medical Center, Cleveland, Ohio ${ }^{11}$ University of North Carolina at Chapel Hill, Chapel Hill, North Carolina ${ }^{12}$ Columbia University, New York, New York ${ }^{13}$ Wake Forest University Health Sciences, Winston-Salem, North Carolina ${ }^{14}$ The Ohio State University, Columbus, Ohio ${ }^{15}$ The George Washington University Biostatistics Center, Washington, District of Columbia ${ }^{16}$ Eunice Kennedy Shriver National Institute of Child Health and Human Development, Bethesda, Maryland
\end{abstract}

\begin{abstract}
Objective-To study the relationship between fetal station and successful vaginal delivery in nulliparous women.

Study Design-This was a secondary analysis from a previously reported trial of pulse oximetry. Vaginal delivery rates were evaluated and compared with respect to the fetal station. Spontaneous labor and induction of labor groups were evaluated separately. Multivariable logistic regression analysis was performed to adjust for confounding factors.
\end{abstract}

Results-Successful vaginal delivery was more frequent with an engaged vertex for spontaneous labor $(86.2 \%$ versus $78.6 \% ; p=0.01)$ and induced labor $(87.7 \%$ versus $66.1 \% ; p<0.01)$. After adjustment, engaged fetal vertex was not associated with vaginal delivery for spontaneous labor (odds ratio [OR] 1.5; 95\% confidence interval $[\mathrm{CI}] 0.95$ to $2.3 ; p=0.08$ ) or for women with induced labor (OR 2.2; 95\% CI 0.96 to $5.1 ; p=0.06$ ).

Copyright $@ 2012$ by Thieme Medical Publishers, Inc.

Address for correspondence and reprint requests Sally Y. Segel, M.D., 01827 SW Palatine Hill Road, Portland, OR 97219 (sysegel@gmail.com)..

Presented at the 30th Annual Society for Maternal Fetal Medicine, February 2010. 
Conclusion-Among nulliparous women enrolled in the FOX randomized trial in spontaneous labor or for labor induction, an engaged fetal vertex does not affect their vaginal delivery rate.

\section{Keywords}

labor; fetal station; vaginal delivery

In early studies by Friedman and Sachtleben, a high fetal station on presentation was associated with a dysfunctional labor pattern. ${ }^{1-4}$ Subsequent studies examined the relationship between fetal station and cesarean delivery and demonstrated that an unengaged vertex at the time of active labor is associated with a significantly increased chance of cesarean delivery. ${ }^{4-7}$ Yet, the relevance of these findings to the present day is uncertain as obstetric practice has been characterized by a decreased frequency of operative vaginal delivery and an increased frequency of cesarean delivery. ${ }^{8}$ The demographic characteristics of reproductive-aged women in the United States have also changed such that the pregnant women are more likely to be older and have a greater body mass index (BMI) ${ }^{9,10}$ Both of these factors have been linked to higher rates of cesarean delivery. ${ }^{11-13}$

Thus, in the context of the present obstetric population and the approach to medical care, the relationship between station at admission for labor and vaginal delivery remains uncertain. This secondary analysis of detailed labor data from the modern era was performed to estimate the association between fetal station at admission and subsequent vaginal delivery.

\section{Methods}

We conducted a secondary analysis of data derived from a randomized clinical trial of fetal pulse oximetry, in which the 14 clinical centers of Eunice Kennedy Shriver National Institute of Child Health and Human Development Maternal Fetal Medicine Units Network ${ }^{14}$ participated. Nulliparous women $\geq 36$ weeks' gestation with a singleton fetus who presented to labor and delivery between May 2002 and February 2005 were offered enrollment in the study. Those who consented were randomized when their cervical dilation was between 2 and $6 \mathrm{~cm}$ and the fetal vertex had reached -1 station. Randomization was performed by a research nurse through an encrypted program in a laptop computer. Women were excluded if they had a temperature $>38^{\circ} \mathrm{C}$, HIV, hepatitis, diabetes mellitus, or maternal cardiac or renal disease. Women with hypertensive disorders were not excluded and were eligible for participation in the study and this analysis. The study was approved by the institutional review board at each center, and written informed consent was obtained from all study participants prior to enrollment.

Trained research nurses who were present and managing the pulse oximeter collected the labor and delivery data. For women who presented in spontaneous labor, fetal station was defined as that determined by the examination upon admission to labor and delivery. For women who presented for an induction of labor, fetal station was defined as that determined by the first examination at the time of induction. Women were excluded from analysis if no examination was recorded within 30 minutes of admission for spontaneous labor or at the initiation of their labor induction. Depending on the clinical center, fetal station was recorded based either on the -5 to +5 scale or the -3 to +3 scale. Acknowledging the 
recommendation of the American Congress of Obstetricians and Gynecologists for using -5 to +5 scale, simple clinical conversion was only possible from the -5 to +5 scale to the -3 to +3 scale. As a result, -5 to +5 station data were converted to the -3 to +3 scale for the purposes of this analysis ( $\triangle$ Table 1 ). This decision was made prior to beginning the analysis.

Fetal station was analyzed both as an ordinal and dichotomous variable. Because the number of cases with station at +1 and +2 was small, these two groups were combined for analyses utilizing station as an ordinal variable. The association of fetal station with vaginal delivery was evaluated using the Mantel-Haenszel chi-square test for trend, and with time to delivery using the Jonckheere-Terpstra test for trend. For the dichotomous analyses, station was categorized according to whether the fetal vertex was engaged, defined as station 0 or below. The association of dichotomous fetal station with vaginal delivery was evaluated using the chi-square test and with time to delivery using the Wilcoxon rank sum test.

Women who presented in spontaneous labor and women who presented for an induction of labor were analyzed separately. Women in spontaneous labor were further divided according to whether their cervical dilation was $\geq 4 \mathrm{~cm}$ or $<4 \mathrm{~cm}$ at admission. The interaction effect of cervical dilation at admission and fetal station as an ordinal variable on vaginal delivery was assessed with logistic regression and on time to delivery with linear regression. The same interaction effect with fetal station as a dichotomous variable on vaginal delivery was assessed with the Breslow-Day test for homogeneity of the odds ratios (ORs) and on time to delivery with the Van Elteren test, a nonparametric test for stratified continuous data. ${ }^{15}$ The association between fetal station and vaginal delivery was additionally analyzed using multivariable logistic regression models that controlled for the following variables chosen by the authors, a priori: maternal prepregnancy BMI, age, and race/ethnicity, as well as birth weight, presence of membrane rupture and cervical dilation at admission, and trial intervention group. Analysis was performed to test the presence of significant multicollinearity between covariates in the regression. Multivariable analyses of the data from the induced labor group also controlled for the occurrence of an elective induction. Assuming $67 \%$ of women would achieve a vaginal delivery and $4 \%$ would be admitted with an engaged fetal vertex, we are able to detect an OR of 2.0 or more with $a=0.05$, statistical power of $80 \%$, nine covariates, and the available number of women in the induced labor group. With similar assumptions, an OR of 1.7 or greater is detectable in the spontaneous labor group. All reported $p$ values are two-sided, and $p<0.05$ was considered significant. No adjustments were made for multiple comparisons. SAS software (SAS Institute, Inc., Cary, NC) was used for analysis.

\section{Results}

Of the 5341 nulliparous women randomized in the fetal pulse oximetry trial, a cervical examination that included fetal station on admission to labor and delivery and met the inclusion criteria with regard to timing was available for $2177 / 3123(69.7 \%)$ of the women admitted in spontaneous labor and 1841/2218 (83.0\%) of the women admitted for induction of labor. The majority of the population eligible for this analysis was Caucasian and 
presented with a cervical dilation $<4 \mathrm{~cm}$, and $19.6 \%$ had a BMI greater than $30 \mathrm{~kg} / \mathrm{m}^{2}$. Demographic and obstetric characteristics at admission are presented in $\mathbf{- T a b l e} 2$.

In the univariable analysis of women who presented in spontaneous labor, lower station of the fetal vertex at presentation was associated with a significantly higher likelihood of vaginal delivery. This relationship was present when fetal station was evaluated either as an ordinal or dichotomous variable ( Tables 3 and 4). The magnitude of this relationship, for women in spontaneous labor, did not differ on the basis of cervical dilation at initial exam ( $p$ $=0.75$, interaction term for ordinal analysis; $p=0.66$, interaction term for categorical analysis). A similar association between station and vaginal delivery was seen for women undergoing labor induction ( $\$ Tables 3 and 4 ). In addition, among those who underwent cesarean, there were no differences between those with an engaged and those without an engaged vertex in the proportion with arrest disorders (spontaneous labor: 65.4 versus $65.7 \%, p=0.98$; labor induction: $57.1 \%$ versus $78.0 \%, p=0.19)$.

Prepregnancy BMI, maternal age, race/ethnicity, cervical dilation and status of membranes at admission, and birth weight were included in the multivariable logistic regression analysis that was performed to adjust for confounding factors. For women in spontaneous labor, an engaged station was no longer significantly associated with more frequent vaginal delivery after this adjustment (adjusted OR 1.5; 95\% confidence interval 0.95 to $2.3 ; p=0.08$ ). For women undergoing labor induction, the multivariable regression model also included a variable to represent elective induction and revealed the lack of a significant association between an engaged fetal station and vaginal delivery after controlling for other factors (adjusted OR 2.2; 95\% confidence interval 0.96 to $5.1 ; p=0.06$ ). In neither the spontaneous labor nor the labor induction cohort was there any interaction between use of fetal pulse oximetry and engaged station ( $p=0.73$ and 0.13 , respectively).

Analysis of time from admission to delivery among women who presented in spontaneous labor revealed a lower fetal station at presentation to be associated with a significant decrease in the duration of labor, although only when station was represented as a dichotomous variable ( $\$ Tables 5 and 6 ). The magnitude of this relationship differed on the basis of cervical dilation at initial exam ( $p=0.01$, interaction term). Among women presenting with a cervix at $<4 \mathrm{~cm}$ dilation, an engaged fetal station was associated with a shorter duration of labor (median 10.0 versus 11.2 hours, $p<0.01$ ), but not among those with a cervix at $\geq 4 \mathrm{~cm}(p=0.48)$. In women who underwent induction of labor, a lower fetal station also was associated with a significantly decreased length of labor, regardless of whether station was analyzed as an ordinal or a dichotomous variable ( $\downarrow$ Tables 5 and 6 ).

\section{Discussion}

In this analysis of data from the Maternal Fetal Medicine Units Network fetal pulse oximetry trial, engagement of the fetal vertex was not associated with a greater probability of successful vaginal delivery in nulliparous women who presented at $\geq 36$ weeks' gestation. These results differ from the results of previous studies. For example, in a study of Nigerian women with active phase labor arrest, Oboro et al reported that an unengaged fetal vertex at admission was associated with a significantly increased risk for cesarean delivery. ${ }^{5}$ In a 
retrospective study, Roshanfekr et al also found a significant increase in cesarean delivery among nulliparous women who presented with an unengaged fetal vertex, even after controlling for confounding factors. ${ }^{6}$ Nevertheless, it should be noted that the large majority (86\%) of women in this study who presented with an unengaged fetal vertex had a successful vaginal delivery. The association between engagement of the vertex at admission and vaginal delivery also was explored by Peaceman et al in their trial evaluating active management of labor. ${ }^{16}$ In their trial, 700 laboring nulliparous women at term were randomized to traditional versus active management of labor. Multivariable analysis demonstrated a significant increase in cesarean delivery in both actively managed labor (OR $2.7,95 \%$ CI 1.2 to 6.0 ) and traditionally managed labor (OR 3.2, 95\% CI 1.6 to 6.3) among women who presented with a fetal station higher than $-1 .{ }^{16}$

The differences in the results of the present analysis from previous results may be due to differences in the demographic characteristics of the patients as well as changes in labor management. One could postulate that increasing maternal age and obesity in pregnant women in concert with a decreasing frequency of operative vaginal deliveries may have altered the association between lack of engagement at admission and subsequent vaginal delivery. Alternatively, the difference in results may reflect the particular inclusion criteria for the fetal pulse oximetry trial and this secondary analysis. Women could not be randomized, or correspondingly included in this secondary analysis, unless the fetal station reached at least -1 . This may imply that higher station at admission is not a risk factor for cesarean birth as long as progress to at least -1 station is made.

The strengths of this secondary analysis include that it has a large sample size and patients from 14 different centers across the United States, which enhance the power to detect a difference as well as external validity. Additionally, ascertainment bias is reduced due to the fact that data were prospectively collected by trained research nurses.

One of the limitations of this study is that the only patients who were included were those who were eligible for the original fetal pulse oximetry trial. Women who presented in active labor and rapidly progressed to delivery may have missed the window for randomization and thus were not included in that trial or this secondary analysis. Also, 94\% of the study population presented with an unengaged vertex, a frequency that is somewhat higher than the range of 70 to $80 \%$ range noted in other studies. ${ }^{5,6}$ In addition, because the demographic characteristics of our cohort are different than certain segments of the U.S. pregnant population, the ability to generalize our findings to all nulliparous women is limited. These circumstances raise the possibility that our findings are not generalizable to the general population. Thirty percent of the cohort that presented with spontaneous labor and $17 \%$ of the cohort that presented for an induction of labor did not have fetal station recorded and were excluded from the analysis. If these women had more complete cervical examinations recorded and could be included in this analysis, our findings could potentially be altered. Last, although the multivariable results did not reach the threshold for statistical significance, the confidence intervals crossed unity by only a small degree, and a larger population may have been able to detect a statistically significant association. 
In summary, this analysis demonstrates that even though many nulliparous women present in labor or for induction with an unengaged vertex, the majority will nevertheless have a vaginal delivery. Moreover, after controlling for multiple potentially confounding factors, station at admission is not significantly associated with the chance of cesarean delivery. Correspondingly, a high or unengaged fetal station on admission does not appear to be a useful predictor of cesarean delivery and should not be used to deter an adequate trial of labor.

\section{Acknowledgments}

The project described was supported by grants from the Eunice Kennedy Shriver National Institute of Child Health and Human Development (NICHD; HD21410, HD27860, HD27869, HD27915, HD27917, HD34116, HD34136, HD34208, HD40485, HD40500, HD40512, HD40544, HD40545, HD40560, and HD36801) and does not necessarily represent the official views of the NICHD or the National Institutes of Health.

The author thanks the following subcommittee members who participated in protocol development and coordination between clinical research centers (Allison T. Northen, M.S.N., R.N.), protocol/data management and statistical analysis (Elizabeth Thom, Ph.D.), and protocol development and oversight (Kenneth J. Leveno, M.D.).

In addition to the authors, other members of the Eunice Kennedy Shriver National Institute of Child Health and Human Development Maternal-Fetal Medicine Units Network are as follows:

The University of Texas Health Science Center at Houston-S. Ramin, M. Day, F. Ortiz, B. Figueroa, S. Shaunfield, M. Messer

University of Alabama at Birmingham-A. Northen, K. Bailey, J. Grant, S. Tate, T. Hill-Webb

Brown University-M. Carpenter, J. Tillinghast, D. Allard, P. Breault, N. Connolly, J. Silva

Case Western Reserve University-MetroHealth Medical Center-C. Milluzzi, C. Heggie, H. Ehrenberg, B. Stetzer

Columbia University—V. Pemberton, S. Bousleiman, H. Husami, V. Carmona, S. South

Drexel University—M. Talucci, M. Pollock, M. Sherman, C. Tocci, E. Selzer

University of North Carolina at Chapel Hill—S. Brody, J. Granados, K. Clark, J. Mitchell, K. Dorman

Northwestern University—A. Peaceman, G. Mallett, N. Cengic, M. Huntley, T. Triplett

The Ohio State University-F. Johnson, S. Fyffe, M. Landon

University of Pittsburgh-M. Cotroneo, M. Luce, H. Birkland, M. Bickus, L. Creswell-Hartman

University of Texas Southwestern Medical Center-K. Leveno, J. Gold, L. Moseley

University of Utah-K. Anderson (University of Utah Health Sciences Center), B. Oshiro (McKay-Dee Hospital), F. Porter (Intermountain Healthcare), K. Jolley (Utah Valley Regional Medical Center), A. Guzman (McKay-Dee Hospital)

Wake Forest University Health Sciences-M. Swain, J. Chilton, C. Leftwich, W. Davido, K. Johnson

Wayne State University—G. Norman, B. Steffy, C. Sudz, S. Blackwell

The George Washington University Biostatistics Center- E. Thom, A. Swanson, F. Galbis-Reig, L. Leuchtenburg

Eunice Kennedy Shriver National Institute of Child Health and Human Development—S. Tolivaisa, K. Howell

MFMU Network Steering Committee Chair (University of Texas Medical Center, Galveston, TX)—G. Anderson, M.D.

\section{References}

1. Friedman EA, Sachtleben MR. Station of the fetal presenting part. I. Pattern of descent. Am J Obstet Gynecol. 1965; 93:522-529. [PubMed: 5891546] 
2. Friedman EA, Sachtleben MR. Station of the fetal presenting part. II. Effect on the course of labor. Am J Obstet Gynecol. 1965; 93:530-536. [PubMed: 5891547]

3. Friedman EA, Sachtleben MR. Station of the fetal presenting part. 3. Interrelationship with cervical dilatation. Am J Obstet Gynecol. 1965; 93:537-542. [PubMed: 5891548]

4. Friedman EA, Sachtleben MR. Station of the fetal presenting part. VI. Arrest of descent in nulliparas. Obstet Gynecol. 1976; 47:129-136. [PubMed: 1250535]

5. Oboro VO, Tabowei TO, Bosah JO. Fetal station at the time of labour arrest and risk of caesarean delivery. J Obstet Gynaecol. 2005; 25:20-22. [PubMed: 16147687]

6. Roshanfekr D, Blakemore KJ, Lee J, Hueppchen NA, Witter FR. Station at onset of active labor in nulliparous patients and risk of cesarean delivery. Obstet Gynecol. 1999; 93:329-331. [PubMed: 10074972]

7. Falzone S, Chauhan SP, Mobley JA, Berg TG, Sherline DM, Devoe LD. Unengaged vertex in nulliparous women in active labor. A risk factor for cesarean delivery. J Reprod Med. 1998; 43:676-680. [PubMed: 9749418]

8. Martin JA, Hamilton BE, Sutton PD, et al. Births: final data for 2007. Natl Vital Stat Rep. 2010; 58:1-85. [PubMed: 21254725]

9. Martin JA, Hamilton BE, Sutton PD, et al. Births: Final data for 2006. Natl Vital Stat Rep. 2009; 57:1-86.

10. Catalano PM, Ehrenberg HM. The short- and long-term implications of maternal obesity on the mother and her offspring. BJOG. 2006; 113:1126-1133. [PubMed: 16827826]

11. Smith GC, Cordeaux Y, White IR, et al. The effect of delaying childbirth on primary cesarean section rates. PLoS Med. 2008; 5:e144. [PubMed: 18597550]

12. Kaiser PS, Kirby RS. Obesity as a risk factor for cesarean in a low-risk population. Obstet Gynecol. 2001; 97:39-43. [PubMed: 11152904]

13. Crane SS, Wojtowycz MA, Dye TD, Aubry RH, Artal R. Association between pre-pregnancy obesity and the risk of cesarean delivery. Obstet Gynecol. 1997; 89:213-216. [PubMed: 9015022]

14. Bloom SL, Spong CY, Thom E, et al. National Institute of Child Health and Human Development Maternal-Fetal Medicine Units Network. Fetal pulse oximetry and cesarean delivery. N Engl J Med. 2006; 355:2195-2202. [PubMed: 17124017]

15. Lehman, EL. Nonparametrics: Statistical Methods Based on Ranks. Holden-Day; San Francisco: 1975.

16. Peaceman AM, Lopez-Zeno JA, Minogue JP, Socol ML. Factors that influence route of deliveryactive versus traditional labor management. Am J Obstet Gynecol. 1993; 169:940-944. [PubMed: 8238153] 
Table 1

Conversion of the -5 to +5 Scale to -3 to +3 Scale

\begin{tabular}{|l|l|}
\hline-5 to +5 & -3 to +3 \\
\hline-5 & -3 \\
\hline$-4,-3$ & -2 \\
\hline$-2,-1$ & -1 \\
\hline 0 & 0 \\
\hline$+1,+2$ & +1 \\
\hline$+3,+4$ & +2 \\
\hline+5 & +3 \\
\hline
\end{tabular}


Table 2

Maternal Demographics and Obstetric Characteristics Stratified by Type of Labor and Documentation of Station on Admission

\begin{tabular}{|c|c|c|c|c|c|c|}
\hline & $\begin{array}{l}\text { Spontaneous } \\
\text { Labor }(n=2177)\end{array}$ & $\begin{array}{l}\text { Spontaneous } \\
\text { Labor without } \\
\text { Recorded } \\
\text { Station }(n=946)\end{array}$ & $P$ & $\begin{array}{l}\text { Induced Labor } \\
(n=1841)\end{array}$ & $\begin{array}{l}\text { Induced } \\
\text { Labor } \\
\text { Without } \\
\text { Recorded } \\
\text { Station }(n= \\
\text { 377) }\end{array}$ & $P$ \\
\hline \multicolumn{7}{|l|}{ Fetal station } \\
\hline Ballotable & $59(2.7)$ & & & $125(6.8)$ & & \\
\hline-3 & $414(19.0)$ & & & $464(25.2)$ & & \\
\hline-2 & $573(26.3)$ & & & $619(33.6)$ & & \\
\hline-1 & $942(43.3)$ & & & $576(31.3)$ & & \\
\hline 0 & $175(8.0)$ & & & $55(3.0)$ & & \\
\hline+1 & $12(0.6)$ & & & $2(0.1)$ & & \\
\hline+2 & $2(0.1)$ & & & 0 & & \\
\hline Engaged & $189(8.7)$ & & & $57(3.1)$ & & \\
\hline Cervical dilation $(\mathrm{cm})$ & $3.0 \pm 1.2$ & & & $1.7 \pm 1.1$ & & \\
\hline Active labor & $810(37.2)$ & & & $110(6.0)$ & & \\
\hline $\begin{array}{l}\text { Membranes ruptured at or before } \\
\text { admission }\end{array}$ & $716(33.0)$ & $352(37.4)$ & 0.02 & $375(20.4)$ & $32(8.5)$ & $<0.001$ \\
\hline Elective induction & & & & $374(20.3)$ & $42(11.1)$ & $<0.001$ \\
\hline Pharmaceutical ripening agent & & & & $492(26.7)$ & $122(32.4)$ & 0.03 \\
\hline Gestational age (wk) & $39.7 \pm 1.2$ & $39.7 \pm 1.3$ & 0.32 & $40.0 \pm 1.4$ & $40.1 \pm 1.4$ & 0.03 \\
\hline Race & & & $<0.001$ & & & $<0.001$ \\
\hline African-American & $804(36.9)$ & 207 (21.9) & & $566(30.7)$ & 78 (20.7) & \\
\hline Caucasian & $1035(47.5)$ & $412(43.6)$ & & $1058(57.5)$ & $257(68.2)$ & \\
\hline Other & $338(15.5)$ & 327 (34.6) & & $217(11.8)$ & $42(11.1)$ & \\
\hline Hispanic/Latino ethnicity & $498(22.9)$ & $418(44.2)$ & $<0.001$ & $323(17.5)$ & $70(18.6)$ & 0.64 \\
\hline Married & $966(44.4)$ & $440(46.5)$ & 0.27 & $962(52.3)$ & $231(61.3)$ & 0.001 \\
\hline Maternal age (y) & $22.9 \pm 5.4$ & $23.9 \pm 5.9$ & $<0.001$ & $23.6 \pm 5.2$ & $25.4 \pm 6.2$ & $<0.001$ \\
\hline Maternal age $\geq 35 \mathrm{y}$ & $92(4.2)$ & $52(5.5)$ & 0.12 & $69(3.8)$ & $37(9.8)$ & $<0.001$ \\
\hline Prepregnancy BMI $\left(\mathrm{kg} / \mathrm{m}^{2}\right)$ & $24.9 \pm 5.8$ & $25.1 \pm 5.8$ & 0.29 & $26.4 \pm 6.5$ & $26.0 \pm 6.4$ & 0.27 \\
\hline Obese (BMI $\geq 30 \mathrm{~kg} / \mathrm{m}^{2}$ ) & $329(15.6)$ & $141(15.6)$ & 0.97 & $433(24.2)$ & $82(22.3)$ & 0.43 \\
\hline Hypertension & & & 0.49 & & & 0.97 \\
\hline None & $2051(94.2)$ & $899(95.0)$ & & $1434(77.9)$ & $298(79.1)$ & \\
\hline Gestational & $59(2.7)$ & $23(2.4)$ & & $184(10.0)$ & $36(9.6)$ & \\
\hline Mild preeclampsia & $60(2.8)$ & $19(2.0)$ & & $198(10.8)$ & $38(10.1)$ & \\
\hline Severe preeclampsia & $7(0.3)$ & $5(0.5)$ & & $25(1.4)$ & $5.0(1.3)$ & \\
\hline Birth weight (g) & $3334 \pm 436$ & $3361 \pm 441$ & 0.15 & $3379 \pm 493$ & $3461 \pm 502$ & $<0.001$ \\
\hline Birth weight $\geq 4000 \mathrm{~g}$ & $150(6.9)$ & $76(8.0)$ & 0.26 & $182(9.9)$ & $50(13.3)$ & 0.05 \\
\hline
\end{tabular}




\begin{tabular}{|l|l|l|l|l|l|l|}
\hline & $\begin{array}{l}\text { Spontaneous } \\
\text { Labor }(\boldsymbol{n}=\mathbf{2 1 7 7})\end{array}$ & $\begin{array}{l}\text { Spontaneous } \\
\text { Labor without } \\
\text { Recorded } \\
\text { Station }(\boldsymbol{n}=\mathbf{9 4 6})\end{array}$ & $\boldsymbol{P}$ & $\begin{array}{l}\text { Induced Labor } \\
(\boldsymbol{n = 1 8 4 1 )}\end{array}$ & $\begin{array}{l}\text { Induced } \\
\text { Labor } \\
\text { Without } \\
\text { Recorded } \\
\text { Station }(\boldsymbol{n}= \\
\mathbf{3 7 7})\end{array}$ & $\boldsymbol{P}$ \\
\hline "Open" oximetry group & $1057(48.6)$ & $496(52.4)$ & 0.05 & $901(48.9)$ & $175(46.4)$ & 0.37 \\
\hline
\end{tabular}

Presented as $n(\%)$ or as mean \pm standard deviation. BMI, body mass index. 
Table 3

Relationship between Fetal Station Represented as an Ordinal Variable and Vaginal Delivery

\begin{tabular}{|l|l|l|l|l|l|l|l|}
\hline & Ballotable & $\mathbf{- 3}$ & $\mathbf{- 2}$ & $\mathbf{- 1}$ & $\mathbf{0}$ & $\mathbf{+ 1 / +}$ & $\mathbf{P}^{\boldsymbol{a}}$ \\
\hline Spontaneous labor & $41 / 59(69.5)$ & $340 / 414(82.1)$ & $432 / 573(75.4)$ & $750 / 942(79.6)$ & $152 / 175(86.9)$ & $11 / 14(78.6)$ & 0.04 \\
\hline Induction of labor & $80 / 125(64.0)$ & $289 / 464(62.3)$ & $382 / 619(61.7)$ & $429 / 576(74.5)$ & $49 / 55(89.1)$ & $1 / 2(50.0)$ & $<0.01$ \\
\hline
\end{tabular}

Data are $n(\%)$ unless otherwise specified.

${ }^{a}$ Mantel-Haenszel chi-square test for trend. 
Table 4

Relationship between Fetal Station Represented as a Dichotomous Variable and Vaginal Delivery

\begin{tabular}{|l|l|l|l|l|}
\hline & Engaged & Not Engaged & $\boldsymbol{P}$ & Odds Ratio (95\% CI) \\
\hline Spontaneous labor & $163 / 189(86.2)$ & $1563 / 1988(78.6)$ & 0.01 & $1.7(1.1,2.6)$ \\
\hline Induction of labor & $50 / 57(87.7)$ & $1180 / 1784(66.1)$ & $<0.001$ & $3.7(1.6,8.1)$ \\
\hline
\end{tabular}

Data are $n(\%)$ unless otherwise specified. CI, confidence interval. 
Table 5

Time from Admission (h) to Delivery Stratified by Fetal Station

\begin{tabular}{|l|l|l|l|l|l|l|l|}
\hline & Ballotable & $\mathbf{- 3}$ & $\mathbf{- 2}$ & $\mathbf{- 1}$ & $\mathbf{0}$ & $\mathbf{+ 1 / + 2}$ & $\boldsymbol{P}^{\boldsymbol{a}}$ \\
\hline Spontaneous labor & $\begin{array}{l}9.4(6.9,11.4) ; n \\
=59\end{array}$ & $\begin{array}{l}9.8(7.0,13.8) ; n \\
=414\end{array}$ & $\begin{array}{l}10.4(7.7,14.0) ; \\
n=573\end{array}$ & $\begin{array}{l}10.4(7.7, \\
13.5) ; n= \\
942\end{array}$ & $\begin{array}{l}8.6(6.6, \\
11.6) ; n= \\
175\end{array}$ & $\begin{array}{l}9.5(6.9, \\
11.2) ; n=14\end{array}$ & 0.27 \\
\hline Induction of labor & $\begin{array}{l}17.2(13.3,24.0) ; \\
n=125\end{array}$ & $\begin{array}{l}17.1(12.3,22.7) ; \\
n=464\end{array}$ & $\begin{array}{l}15.9(11.7,21.0) ; \\
n=619\end{array}$ & $\begin{array}{l}11.1(8.3, \\
15.2) ; n= \\
576\end{array}$ & $\begin{array}{l}8.8(7.0, \\
12.1) ; n= \\
55\end{array}$ & $\begin{array}{l}12.8(10.0, \\
15.6) ; n=2\end{array}$ & $<0.001$ \\
\hline
\end{tabular}

Data are median (interquartile range) unless otherwise specified. The time from admission to delivery for women who presented in spontaneous labor ranges from 2.1 to $37.8 \mathrm{~h}$ and for women who presented for an induction of labor ranges from 2.4 to $76.1 \mathrm{~h}$.

$a_{\text {Jonckheere-Terpstra test for trend. }}$ 


\section{Table 6}

Time from Admission to Delivery (h) Stratified by Engagement of the Fetal Vertex ${ }^{a}$

\begin{tabular}{|c|l|l|l|}
\hline & Engaged & Unengaged & $P$ \\
\hline Spontaneous labor & $8.7(6.6,11.6) ; n=189$ & $10.3(7.6,13.7) ; n=1988$ & $<0.001$ \\
\hline Cervix $<4 \mathrm{~cm}$ & $10.0(7.4,12.6) ; n=80$ & $11.2(8.5,14.8) ; n=1287$ & $<0.01$ \\
\hline Cervix $\geq 4 \mathrm{~cm}$ & $8.5(6.4,10.5) ; n=109$ & $8.5(6.0,11.2) ; n=701$ & 0.48 \\
\hline Induction of labor & $8.9(7.1,12.1) ; n=57$ & $14.6(10.2,20.5) ; n=1784$ & $<0.001$ \\
\hline
\end{tabular}

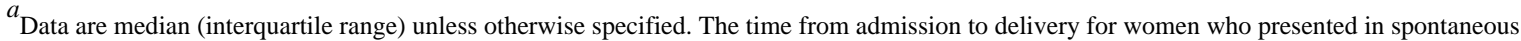
labor ranges from 2.2 to $34.4 \mathrm{~h}$ in those with an engaged fetal vertex and 2.1 to $37.8 \mathrm{~h}$ in those with an unengaged fetal vertex. The same time for women who presented for an induction of labor ranges from 2.1 to $23.3 \mathrm{~h}$ in those with an engaged fetal vertex and 2.4 to $76.1 \mathrm{~h}$ in those with an unengaged fetal vertex. 